\title{
Vicente Sáenz y el amor a la patria de José Martí: José Martí en la Palabra DE VICENTE SÁENZ
}

\begin{abstract}
Resumen
El ensayista costarricense Vicente Sáenz hace un homenaje a José Martí en su ensayo Raíz y ala, publicado en 1953, en la ciudad de México donde residía. El ensayo recorre la vida de Martí desde su desarrollo intelectual, su compromiso político y estético. Un ensayo valioso de un costarricense hacia la emblemática figura del americanista más reconocido del continente.
\end{abstract}

Palabras clave: José Martí, Vicente Sáenz, educación, libertad, soberanía, patria, nacionalismo, identidad, América Latine, Caribe, Centroamérica, política.

\begin{abstract}
Costa Rican essay writter Vicente Sáenz pays homage to José Martí in its essay Raiz y Ala, published in 1953, in the city of Mexico, where he resided. The essay runs Martí life from their intellectual development, his political and aesthetic commitment. A valuable essay by a Costa Rican to the emblematic figure of the best known Americanist of the continent.
\end{abstract}

Key Words: José Martí, Vicente Sáenz, education, freedom, sovereignty, homeland, nationalism, identity, America Latine, Caribbean, Central America, political.

Setenta y cinco años después de que Costa Rica alcanzara la independencia del imperio español, nace en Cartago, Vicente Sáenz Rojas (1896), en los finales de esa etapa conocida como la más liberal en la historia de la nación. Si bien es cierto fue una época signada por un estado sociopolítico de impronta patriarcal, militarista y clasista, no podría decirse que presentara dichos rasgos del mismo modo que otros países centroamericanos y del Caribe, donde las sociedades eran aún más patriarcales, marcadas por profundas desigualdades económicas y étnicas, y con gobiernos más autoritarios y castrenses.

Fue este el momento de pleno auge del cultivo y la exportación del café, lo cual produjo importantes transformaciones económicas tanto en el desarrollo

Macarena Barahona Riera.

Investigadora, docente y catedrática de la Escuela de Estudios Generales, Centro de Investigaciones en Ciencias Políticas. Universidad de Costa Rica. Autora de ensayos sobre derechos políticos de la mujer, cultura política, guerra civil en Costa Rica, literatura y poesía. interno del país (tal es el caso de la propiedad de la tierra y la estructura productiva) como en el sistema de vínculos mercantiles externos (ejemplo de ello lo constituye el establecimiento de relaciones de dependencia económica con Inglaterra primero, y con Estados Unidos después, ya que ambas potencias eran las vías para el aseguramiento de la actividad comercial que incluía, desde el apoyo al sostenimiento de una infraestructura para el transporte y trasiego del grano, hasta la garantía de un mercado para la exportación. Los cambios también se hicieron sentir en el plano social, al agudizarse aún más el desequilibrio ya existente entre los diversos sectores. 
"José Martí",
ilustración por
Bastardilla.

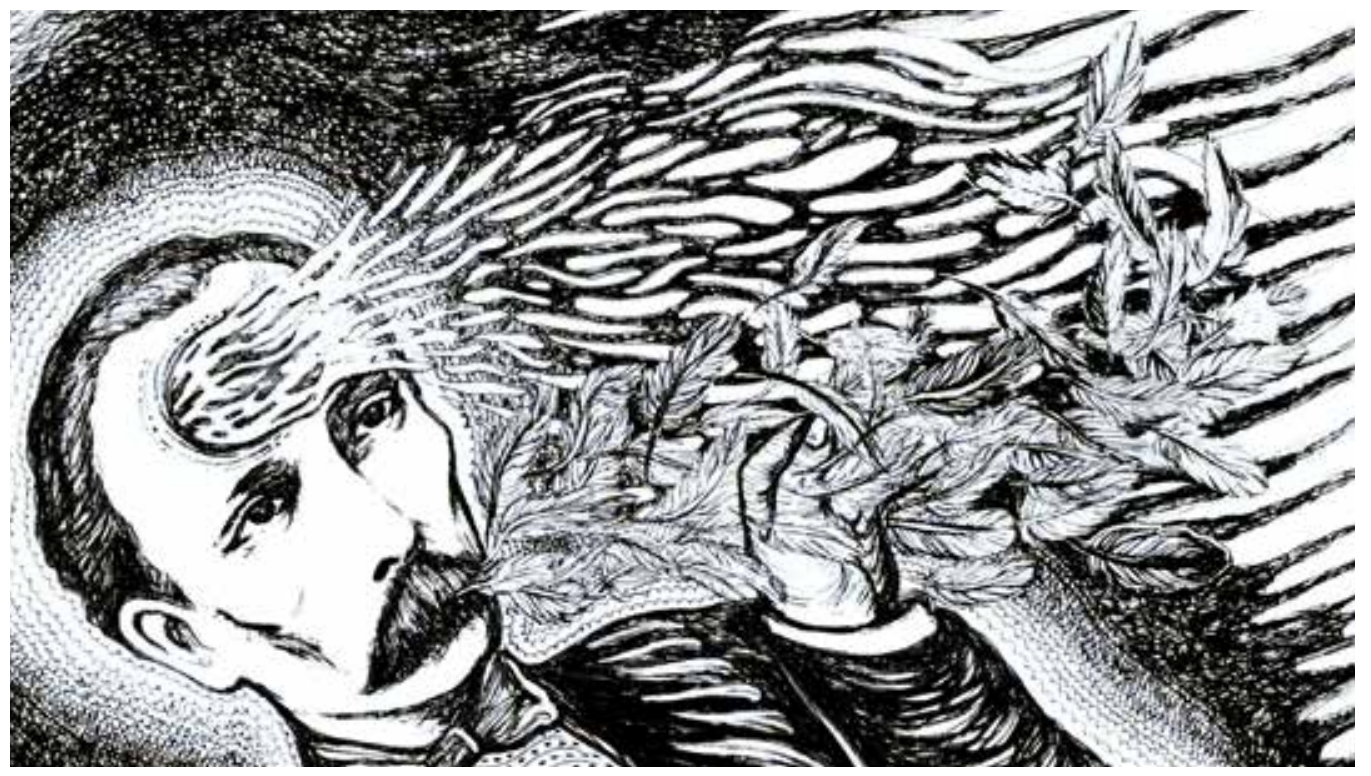

Vicente Sáenz se formó en un ambiente político con fuerte influencia del pensamiento anarquista y socialista. La preeminencia de dichas tendencias favoreció la creación de las primeras organizaciones de ideología clasista a favor de la reivindicación los derechos de los trabajadores. Ello dio paso al desarrollo de un movimiento social obrero (fundamentalmente en aquellos centros de construcciones de grandes obras de transporte como trenes, puertos, carreteras, el Canal de Panamá, etc.) que luchaba por la instauración de nuevas formas de relaciones productivas tanto para la nueva economía cafetalera como para el modelo de enclave bananero promovido por Estados Unidos. En este contexto surge el primer Partido Socialista (1920) en defensa de las necesidades de la clase obrera, del cual Vicente Sáenz sería miembro activo como periodista intenso y escritor polémico de profunda convicción antiimperialista.

La Revolución proletaria rusa de 1917 (y sus acontecimientos posteriores) repercutió en el pensamiento de los costarricenses comprometidos, generando no solo un incremento de los movimientos populares en el país, sino también una ampliación en los objetivos de lucha. La invasión de Estados Unidos a Nicaragua en 1919, por ejemplo, contó con no pocos detractores en Costa Rica que mostraron su oposición a través de publicaciones periódicas, manifestaciones, declaraciones, discursos, etc. por considerar el acontecimiento como una amenaza. El movimiento insurgente dirigido por Augusto César Sandino que luchaba contra la presencia militar del Ejército norteamericano en Nicaragua fue visto en el ámbito cultural y social de Costa Rica con profunda simpatía. El sandinismo se convierte entonces en la primera guerrilla centroamericana que produce una ola generacional de apoyo y solidaridad. Esto se observa claramente en la prensa de la época (La Tribuna, La Prensa Libre, Trabajo, entre muchos otros diarios y semanarios), donde se evidencia un respaldo a los grupos revolucionarios contra la injerencia norteamericana primero, y luego, contra la dictadura de Somoza, apoyada por el gobierno de Estados Unidos. Vicente Sáenz Rojas percibió las intenciones solapadas del país norteño y al respecto expresó:

La protección material y moral a los dictadores solamente ha servido para que estos estrangulen a los pueblos, y cedan miserablemente la soberanía de la nación. Desde la ruptura del pacto federalista de las repúblicas cen- 
troamericanas - la independencia del 15 de Setiembre de 1821 y posteriormente la formación de las Provincias Unidas de Centro de América, creada con el decreto del 1 de julio de 1823, firmado en Guatemala- en 1821, la política colonialista de los Estados Unidos de América se ha enfrascado en un concepto erróneo. Nicaragua no ha recibido la influencia de la buena amistad ni la protección que debería esperar para su mejor desarrollo y prosperidad (Sáenz, 1986, p. 460)

En otro texto también propone: "Bien sabía Martí, desde que estudiaba en la biblioteca del señor Mendive, que a la libertad de Cuba, como a la libertad de Puerto Rico, no sólo se opusieron las autoridades peninsulares, multiplicando las matanzas de campesinos y de los más destacados jefes rebeldes, sino también los poderosos intereses norteamericanos" (Sáenz, 1955, p. 85).

El costarricense, en su libro de homenaje a José Martí, explica que el tránsito que dirige las rutas canaleras de Panamá y Nicaragua (como otros hechos de semejante índole que han tenido lugar a lo largo de la historia) ha sido un mecanismo de control imperialista "mediante la fuerza, la diplomacia del dólar, la traición y el entreguismo - ¡lo peor de Estados Unidos y lo peor de Hispanoamérica! para propiciar los tratados Hay-Bunau Varilla y Bryan-Chamorro" (Sáenz, 1955, p. 89)

Así fueron las primeras décadas de la vida de don Vicente que definieron su carácter. Algunos de los títulos de sus libros bastan para hacernos una idea de las banderas éticas que otearon sus horizontes: Norteamericanización de Centroamérica, Traidores y déspotas de Centroamérica, Cartas a Morazán, Centroamérica en pie, Elogio a Francisco Morazán, Rompiendo cadenas (Latinoamericanas) Hispanoamérica contra el coloniaje y España Heroica. El filósofo costarricense Barahona Jiménez da la siguiente valoración de su labor:

En todas sus obras se percibe la misma indignación, la misma agresividad, el mismo amor por las cosas de nuestro mundo, por su pasado, por su sangre, sus tradiciones, su cultura y el mismo optimismo por un futuro feliz, pleno de desarrollo para nuestros pueblos y para la dignificación del hombre latinoamericano. (Barahona, 1977, p.199)

De estaicente Sáenz viajó por el continente americano y viajó a España Republicana y en guerra. Testimonio de esta participación como periodista e internacionalista es la serie de artículos publicados en la prensa costarricense (La Tribuna) y editados luego como folleto independiente ese mismo año bajo el título España en sus gloriosas jornadas de julio y agosto de 1936.

En igual fecha pone en circulación su periódico Liberación, y como dato interesante que hace patente su solidario compromiso hispanoamericano con las luchas que se libraban, están sus cartas con Pablo de la Torriente Brau, quien desde Nueva York le escribía para solicitarle editar una colaboración y le enviaba ejemplares de su revista Frente Único, a lo cual Vicente le contestaba agradeciéndoles e insistiendo sobre su afiliación política de apoyo para Cuba.

Resulta importante en nuestros días no desconocer los nexos entre nuestros pueblos, y este es un ejemplo de ellos. Dos intelectuales comprometidos vinculados por sus obras y espíritu solidario, unidos por los destinos: ambos escritores-periodistas que coincidieron en la República Española. Dos meses (julio y agosto) Vicente Sáenz estuvo en España participando en actividades de intelectuales y artistas y divulgando los hechos y enfrentamientos contra el gobierno de la República en diversos periódicos. Coincidió en agosto con la llegada del cubano-español Torriente-Brau quien -empeñado en aportar su solidaridad-viaja a España en ese mes para 
fungir como comisario político de la Brigada del V Regimiento, dirigido por el poeta Miguel Hernández, con el cual, el 19 de diciembre, Torriente-Brau encontrará la muerte en batalla. En dicho cuerpo, entre otros, pelea también el costarricenseespañol Adolfo Braña residente en el país quien, al igual que Sáenz, fue miembro del Partido Comunista de Costa Rica.

A principios de la convulsa década de los cuarenta, Vicente Sáenz emigra a México donde fallece en 1963, no sin antes haber alcanzado una fructífera vida intelectual en las Universidades de la capital.

\section{Martí en Vicente Sáenz: raíz y ala del Ifbertador de cuba}

Vicente Sáenz nos ha legado - dentro de su extensa obra de carácter socialista y antiimperialista - este hermoso libro Martí: Raíz y ala del Libertador de Cuba, publicado en homenaje al centenario de su natalicio, en 1953, por la Editorial América Nueva de la Ciudad de México. A sesenta años de la publicación de este ensayo recojo sus palabras que tanto hoy me inspiran por lo diáfano y auténtico de su pluma y pensamiento.

Sáenz hizo un recorrido por la vida de José Martí, una cronología de sucesos de ese gran hombre que pareciera, en la tensión del escritor, contener desde el inicio juvenil un eco de héroe, del destino implacable, que solo los semidioses, los poseedores del "areté" griego, viven, y es esto lo que ardía en la sangre que pulsaban las venas del criollo José Martí.

Nos habla del cubano que amó a su patria explotada por potencias mundiales, del anhelo único de una libertad e independencia, y un concepto de soberanía que sigue incólume.

El autor nos trasmite en este libro su mensaje, martiano, lleno de energía y vehemencia: "Se diría que Vicente Sáenz se siente llamado a clamar por plazas y caminos, a los cuatro vientos, pero sobre todo de Norte a Sur, por todo el continente, un mensaje de rebeldía, de inconformidad con la situación imperante en nuestros países, tanto en lo político como en lo social, cultural y económico" (Barahona, 1986, p. 199).

\section{La generación del centenario: Cuartel Moncada eco martiano}

El libro Martí: Raíz y ala del Libertador de Cuba, publicado en el año 1953 nos hace recordar, a su vez, a los jóvenes cubanos de ese entonces, conocidos como "la generación del centenario", que reconocieron la inspiración de José Martí en el Asalto al Cuartel Moncada el 26 julio de ese mismo año, reiniciando así el proceso emancipatorio que culminaría con el triunfo de la Revolución Cubana en 1959.

Los conceptos de juventud, de vida y muerte, de soberanía, son elementos esenciales que conforman el de ser humano. El siguiente texto lo transcribe Sáenz para dar la idea del sentir martiano ante los impactantes hechos que conmovieron al mundo desde Chicago con motivo de la manifestación obrera del 1 de mayo de 1886, un sentir que no pudo ocultar en su admiración por estos mártires y su proceder ante la muerte que describiera para La Nación de Buenos Aires:

Plegaria es el rostro de Spies; el de Fisher, firmeza; el de Parsons, orgullo rabioso; Engel hace reír con un chiste corchete... Resuena la voz de Spies, mientras están cubriendo las cabezas de sus compañeros, con un acento que a los que le oyen les entra en las carnes: La voz que vais a sofocar 
será más poderosa en lo futuro, que cuantas palabras pudiera yo decir ahora... Fischer dice, mientras atiende el corchete a Engels: Este es el momento más feliz de mi vida. (Sáenz, 1955, p. 92)

De esta manera Vicente Sáenz nos muestra a Martí desde su propia escritura, a ese Martí que desde que se hizo responsable de la carta que lo lleva al presidio, vivió las mismas emociones que manifiesta ante la muerte el líder obrero Fischer: "¿cómo el entrar en una muerte útil, en una muerte heroica, sería el momento más feliz de la vida?" (Sáenz, 1955, p. 92) Y es que la muerte está concebida por el patriota cubano como una fuente liberadora, que en fluidos constantes unen a seres sin importar el tiempo ni el espacio. Martí se une a las palabras del Mártir de Chicago, adhiriendo su espíritu a esa entrega hacia los demás.

Martí, en la última carta que escribe a su amigo Manuel Mercado, exclama: "Hay afectos de tan delicada honestidad" (Sáenz, 1955, p. 94). Son estas las últimas palabras de Martí que transcribe Vicente Sáenz en su libro, empeñado en profundizar en ese espíritu apasionado por la libertad de su patria, razón primera de su lucha por los pueblos latinoamericanos, que llevaría, como ética y compromiso, en su vida y obra de intelectual y maestro. Esa delicada honestidad que resulta de la firme y contundente razón de ser de los hombres y mujeres que creyeron, y creen en la libertad y la dignidad de nuestras patrias, y que solo se alcanza en la condición martiana de "tener limpio y entero el corazón". (Sáenz, 1955, p.121).

¡No se equivoquen los que subestiman tantos sufrimientos $y$ dolores, tantas vidas cercenadas, tanta lucha por la libertad y por la democracia! Esto ha formado una conciencia. No conocerá pueblo a la humanidad...que no sea digno

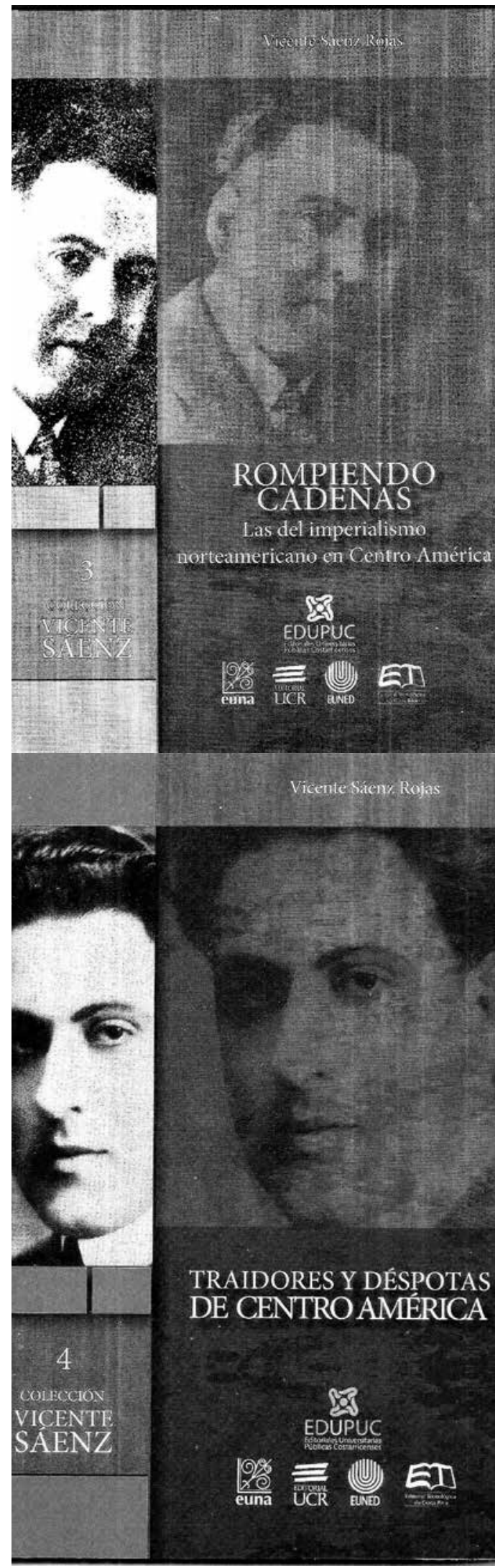


El grito de Dolores y otros ensayos.

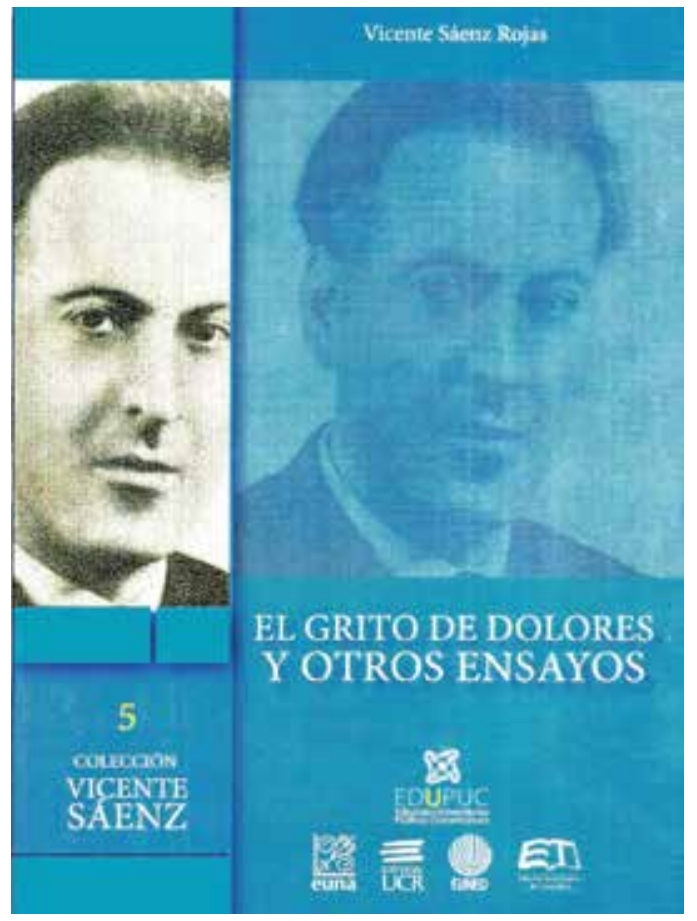

tinente, dejando tras de sí alas y raíces: de que lo traten los de arriba con honradez y con justicia. Los que no están preparados son los otros: los enemigos natos de la democracia; las castas privilegiadas, que desean conservar su libertad para explotar al prójimo, los militares y los déspotas, que confunden su oficio con asaltar la ley, fusilando por parejo a quien se les ponga por delante. Los pueblos entre tanto, $\tan$ calumniados y tan difamados, pecan más de nobles y de generosos. (Sáenz, 1986, p.1533

Don Vicente Sáenz une su corazón al de José Martí en su bella prosa, elaborada para el deleite de ojos jóvenes que prosiguen en sus empeños latinoamericanistas, hermanando los sentidos de libertad, patria y soberanía. Se despide en su homenaje viendo a Martí volar, hacia Cuba, hacia el Con-

Y sigue galopando: hacia Cuba, hacia su bandera, hacia lo alto. Y siente que su corcel se eleva también, como un Pegaso. Y vuela, vuela el jinete hacia la inmortalidad, abrazado, poseído de la muerte que lo hace rodar exánime por tierra...Vive y seguirá viviendo, como faro, en lo más alto del Continente. Y como guía, para no extraviarnos, en lo más hondo de la conciencia hispanoamericana. (Sáenz, 1955, p. 97)

Moravia, Costa Rica. Junio del 2014.

\section{Bibliografía}

1. Barahona Jiménez, Luis. (1977) El pensamiento político en Costa Rica. San José: Editorial Fernández Arce.

2. Barahona Jiménez, Luis (1986) Las ideas políticas en Costa Rica. San José Ministerio de Educación Pública.

3. Martí, José. (1986) "Simón Bolívar". En: Ideas en torno de Latinoamérica. México D.F.: UNAM.

4. Sáenz Rojas, Vicente. (1955) Martí: Raíz y ala del Libertador de Cuba. México D.F.: Editorial América Nueva.

5. Sáenz Rojas, Vicente. (1936) España en sus gloriosas jornadas de julio y agosto de 1936. San José: Imprenta La Tribuna.

6. Sáenz Rojas, Vicente. (1986) "Pasado, presente y porvenir de Centroamérica". En: Ideas en torno de Latinoamérica. México D.F.: UNAM. 